\title{
Isolation and Identification of Streptomyces ramulosus from Soil and Determination of Antimicrobial Property of its Pigment
}

\author{
Saba Azimi', Majid Basei Salehi', Nima Bahador ${ }^{2}$ \\ 1. Department of Microbiology, Kazeroon Branch, Islamic Azad University, Kezeroon, Iran \\ 2. Department of Microbiology, Shiraz Science and Research University, Shiraz, Iran
}

Received:16 Apr 2018;Accepted:02 Jun 2018;

ABSTRACT

Background and Objective: Pigment production by microorganisms is important due to more rapid growth, higher efficiency, easier extraction, and antimicrobial effects compared to other methods. The aim of the present study is to isolate and identify antibiotic pigment-producing actinomycetes from the soil of the Persian Gulf and to evaluate the antibiotic activity of their pigments in the second half of 2014. Given that pathogenic bacteria increasingly become more resistant to common antibiotics, there is a need for new antibiotics.

Methods: A total of 80 soil samples were collected from different areas and after preparing different dilutions $\left(10^{-1}-10^{-7}\right)$, each sample was cultured on nutrient agar medium, specific Starch Casein Agar (SCA), and the International Streptomyces Project 2 (ISP2) media. Then, the actinomycete colonies were selected based on pigment production; pigments were extracted using sediment extraction with ethyl acetate; and the antibacterial property of their pigments were evaluated. The structure of colored extract compounds was identified by Thin layer chromatography (TLC). Molecular identification of the microorganisms was performed by $16 \mathrm{~S}$ rRNA PCR.

Result: The highest antibiotic effect of the pigments was observed in pathogenic bacterium S. aureus and Bacillus cereus, respectively. The lowest antimicrobial activity of the pigments was observed in Escherichia coli bacterium. All the studied fungi were resistant to the studied pigments.

Conclusion: Since natural pigments at an appropriate dose are healthier than the chemical ones, using them is beneficial in various industries, such as antibiotics production. Also, by determining the structure of pigments and eliminating their toxic groups, they can be used in different industries.

Keywords: Actinomycete, Pigment, Antimicrobial property

Corresponding Information: Saba Azimi; Department of Microbiology, Kazeroon Branch, Islamic Azad University, Kezeroon, Iran; Emali: sabaazimi2030@ gmail.com

Copyright $(\subset$ 2018. This is an open-access article distributed under the terms of the Creative Commons Attribution-noncommercial 4.0 International License which permits copy and redistribute the material just in noncommercial usages, provided the original work is properly cited.

\section{Introduction}

Actinomycetes are Gram-positive terrestrial bacteria (1). In most actinomycete species, DNA base composition is comprised of $63-$ $78 \%$ guanine + cytosine $(\mathrm{G}+\mathrm{C})$, which is more than other bacteria (2). These bacteria are heterotrophic, filamentous, rod-shaped, aerobic, immotile, and asexual spore-forming (3). Actinomycetes have numerous and extensive applications in medicine, pharmacy, agriculture, and biotechnology, so that half of the antibiotics produced and consumed in the world, have originated from actinomycetes (4). 
Of 23.000 secondary metabolites produced by actinobacteria, about 10.000 are produced by actinomycetes, among which antibiotics are the most important secondary metabolites; more than $60 \%$ of the known antibiotics are produced by actinomycetes (5). These bacteria can be detected in culture media with tough and leathery colonies containing abundant pigments. The colonies has various colors. Pigment production is one of the physiological properties of actinomycetes (6).

Most of the colors currently used in the production process of food, cosmetics, and pharmaceutical products, have various adverse effects, thus a global trend has emerged to produce pigments from natural sources (7). Natural pigments are produced by two major sources, namely plants and microorganisms. Pigment production from microorganisms is beneficial due to their simple and rapid growth, low-cost culture medium, easier extraction, independence on weather conditions, and wide variety of colors compared to other biological resources (8). Recent studies have shown that some of these pigments have important biological functions, including antibiotic, antifungal, antitumor, and immunosuppressive activities, hence many of them have potential chemotherapeutic effects. In general, colored metabolites of microorganisms have various functions in different industries (9). In the present study, 25 actinomycetes were isolated from the soils of different regions during 4 months. The aim of this study was to identify the antibiotic pigments of the actinomycetes.

\section{Materials and Methods}

\section{Sample collection}

A total of 70 soil samples were collected from different regions of Fars province. To isolate actinomycetes, $1 \mathrm{~g}$ of soil was added to $9 \mathrm{ml}$ of sterile distilled water and serial dilutions $\left(10^{-1}\right.$ to $10^{-7}$ ) were prepared and cultured linearly on Starch Casein Agar (SCA), and International
Streptomyces Project 2 (ISP2) specific media for purification. Then, all cultured plates were incubated at $30^{\circ} \mathrm{C}$ for 4-7 days (6). After incubation, colonies with the highest color intensity were selected and cultured again for pigment extraction.

\section{Identification of actinomycete bacteria}

Initial tests, including simple staining and determination of micromorphological characteristics, were performed to identify actinomycetes. The identification of biochemical characteristics of isolates, such as carbohydrate fermentation, nitrate reduction, oxidase, urease, bile esculin tests, were performed using Api biochemical kits (Coryne bioMerieux), and the results were recorded.

\section{Pigment extraction}

The spores of actinomycetes were scraped from the surface of media, inoculated into nutrient liquid medium, and incubated in a rotary shaker at $120 \mathrm{rpm}$ at $28^{\circ} \mathrm{C}$ for 48 hours. To extract the pigments, $5 \mathrm{ml}$ ethyl acetate was added per $5 \mathrm{~g}$ of the biomass, and then the colored supernatant solution was isolated after centrifugation at 3500 rpm for $15 \mathrm{~min}$ and stored in an oven at $50^{\circ} \mathrm{C}$ until complete elimination of the solvent (7).

\section{Evaluating the antifungal properties of the pigments on pathogenic bacteria and fungi}

In this study, well diffusion method was used to investigate the antimicrobial activity of the pigments. In this method, initially the pigment extract was prepared from actinomycete liquid culture medium, and then the pathogenic bacteria were cultured in Mueller-Hinton agar medium and then wells were created and the filtered extract was added to the wells.

Cultured plates were incubated at $30^{\circ} \mathrm{C}$ for 2-3 days. An inhibition zone was created around 
the wells due to the presence of antibiotic. Stronger actinomycetes were selected based on the diameter of these zones. The larger the diameter of the inhibition zone, the stronger was the antibiotic activity of actinomycete pigments. The pathogenic bacteria Staphylococcus aureus, Bacillus cereus, Escherichia coli, Pseudomonas aeruginosa, Shigella dysenteriae, Citrobacter freundii, Klebsiella pneumoniae, Serratia marcecens and fungi Aspergillus niger and Candida albican, were used to evaluate the antimicrobial properties of the pigments.

\section{Purification of pigments by chromatography}

The obtained pigments were purified using thin-layer chromatography method. To find out the best solvent for pigment extraction, different solvents, including methanol, chloroform, acetic acid, butanol, and water were used with different ratios. Butanol:acetic acid:water (70:20:10 and 60:30:10) and chloroform:methanol (60:40, 50:50, 70:30, 30:70, 80:20 and 20:80) solvents were used in this study.

A small amount of the pigment dissolved in ethyl acetate was placed at the bottom chromatography paper, then was put in a container containing different ratios of solvent as the mobile phase. The lids of containers were closed to prevent the evaporation of solvent. The solvent (mobile phase) ran until it reached about $0.5 \mathrm{~cm}$ below the top of the chromatography paper. The paper was dried at room temperature.

\section{Molecular identification of antibiotic pigment- producing actinomycetes using $16 \mathrm{~S}$ rRNA method}

DNA extraction was performed using a bacterial genomic DNA extraction kit (Fermentas K0512) according to the instructions of the manufacturer. To perform the PCR reaction, master mix was prepared. To prepare a $25 \mu \mathrm{l}$ volume of master mix, $18 \mu \mathrm{l}$ of sterile distilled water, $2.5 \mu 1$ of $\mu 1$ of 10X PCR buffer (CinnaGen
Co., Iran), $0.75 \mu 1$ of $\mathrm{MgCl}_{2}$ (CinnaGen Co., Iran ), $0.5 \mu 1$ of dNTP mix (CinnaGen Co., Iran ), 1 $\mu \mathrm{l}$ of forward and reverse primers (concentration, of $10 \mathrm{pM} / \mu \mathrm{l})($ Table 1$), 0.25 \mu 1$ of polymerase enzyme (CinnaGen Co., Iran), and $1 \mu 1$ of template DNA, were used.

PCR reaction was performed in a thermocycler with initial denaturation of $94^{\circ} \mathrm{C}$ for $1 \mathrm{~min}$, followed by 35 cycles at $94^{\circ} \mathrm{C}$ for $1 \mathrm{~min}, 40^{\circ} \mathrm{C}$ for $1 \mathrm{~min}, 52^{\circ} \mathrm{C}$ for $30 \mathrm{~min}$, and $72^{\circ} \mathrm{C}$ for $1 \mathrm{~min}$, and $72^{\circ} \mathrm{C}$ for $4 \mathrm{~min}$ for final elongation.

Then, to ensure that 16S rRNA gene amplification was performed, the PCR product underwent electrophoresis as follows: After solidification of $1 \%$ gel agarose, it was placed in the electrophoresis tank containing TBE 100x buffer, then $5 \mu \mathrm{l}$ of each PCR product and standard DNA ladder were loaded into each well of the gel and electrophoresis was carried out for $1 \mathrm{~h}$ at $70 \mathrm{~V}$. The electrophoresis gel was placed on a UV transilluminator to visualize the bands of PCR products and the marker.

DNA markers containing DNA fragments of predetermined length, were used to confirm the accuracy of the products. The real size of the products was obtained by comparison between bands of PCR products and the marker. The PCR product of 16S rRNA gene was sent to the Ampliqon Company (South Korea) for sequencing.

Table 1

The sequence of forward and reverse primers for 16S rRNA gene

\begin{tabular}{cc}
\hline Primers & $\mathbf{5}, \boldsymbol{\rightarrow 3}$, \\
\hline 16S_27F & AGAGTTTGATCMTGGCTCAG \\
\hline 16S_1492R & ACGGYTACCTTGTTACGACTT \\
\hline
\end{tabular}

\section{Results}

The colony of strain No. 4 had a good growth on ISP2 and SCA media. The colony was creamy white and the obtained pigment was brown. 


\section{Biochemical identification by Api kits}

The actinomycete bacteria was determined to belong to the Streptomyces family by investigation of biochemical characteristics using Api kits.

In our study, it was found that the ethyl acetate is the best solvent for the extraction of actinomycetes pigments. The colors of the extracted pigments were light and dark brown, yellow, red, white, milky, dark green, and black colors, among which the brown pigment had the best antibiotic effect on pathogenic bacteria.

The most antibiotic effects of the pigment of actinomycete strain No. 4 was on pathogenic bacteria of Bacillus cereus and C. freundii, respectively. No effects were observed on other pathogenic bacteria. Also, the fungi A. niger and C. albicans were resistant to the pigment.

The number of compounds present in the pigments of these microorganisms was investigated by thin-layer chromatography. Pigments were dissolved in $50 \mathrm{ml}$ of ethyl

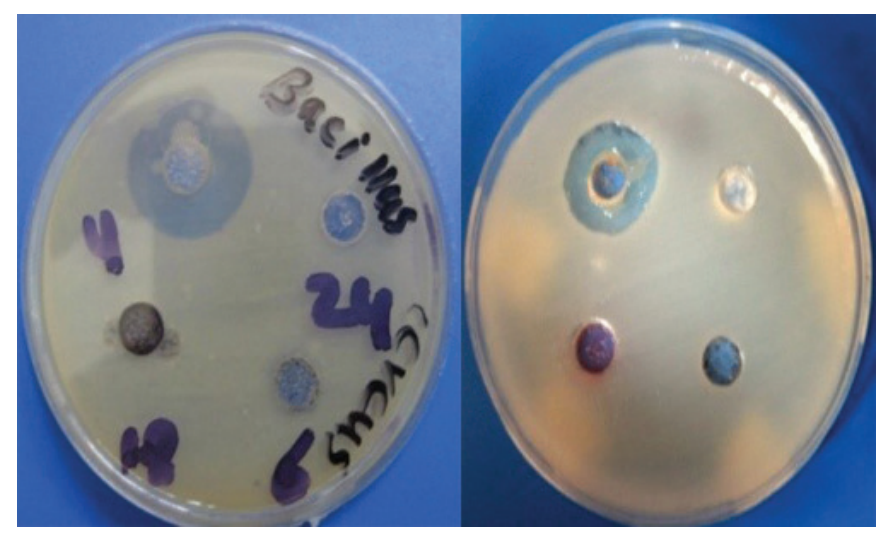

Fig. 1

The antimicrobial effect of strain no. 4

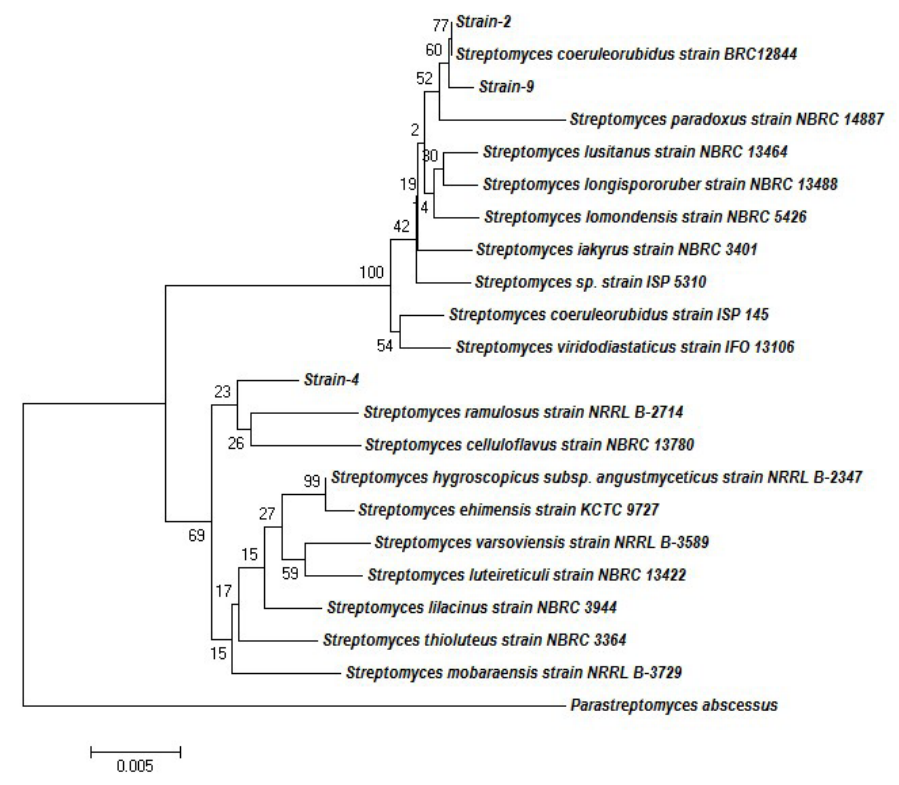

Fig. 2

Phylogenetic tree indicating the position of strain no.4 among similar bacterial species 
acetate. Using a solvent mixture of chloroform and methanol (70:30), ethanol, acid acetic and water $(60: 40: 10)$, the separation process was better performed and only one colored spot appeared on chromatography paper, indicating the presence of a pure compound.

The samples were identified by BLASTN analysis of the obtained sequence in GenBank database (http://blast.ncbi.nlm.nih.gov).

Strain no. 4 was $98.88 \%$ similar to Streptomyces ramulosus strain NRRL B-2714 and different in 15 nucleic acids. The phylogenetic tree was built by neighbor-joining algorithm using the sequences of 16S rRNA gene of the studied strain (obtained by sequencing of PCR product) and similar bacterial species (obtained by BLASTN analysis of each studied strain.

\section{Discussion}

Today, antibiotic resistance has become a serious problem in the treatment of infectious diseases. Therefore, development of alternative antibiotics is of utmost importance (10). From 10000 known microbial metabolites, about 150$160(0.2-0.3 \%)$ compounds have been proved as effective compounds, among which the metabolites of actinomycetes (named antibiotics), are of considerable value, so that hundreds of centers all over the world are currently working in the field of isolation of new potent strains of actinomycetes and extraction of antibiotics substances (11).

Antibiotics are among the most important secondary metabolites produced by actinomycetes, and more than $60 \%$ of known antibiotics are produced by them (12). In recent years, secondary metabolites, pigments of microorganisms, and their biosynthesis pathways have been the subject of much attention (13). Scientifically, fermentation of microorganisms, such as fungi and bacteria could be a valuable source for the production of colored substances, thus looking for environmentally friendly renewable resources is an essential need for the production of colored substances (14). The reason for attention to the microbial pigments is that they are natural, safe, and have nutritional and medicinal properties. Pigment production by microorganisms is controllable and independent of seasonal and climatic conditions (15). Recent studies have shown that some of these pigments have important biological functions, including antibacterial, antifungal, antitumor, and immunosuppressive activities, hence most of them have potential chemotherapeutic effects $(16,17)$.

Mayuran et al. (2006) isolated an actinomycete strain, Streptomyces hygroscopicus subsp. ossamyceticus (strain D10), which produced a yellow color pigment with effective antibacterial and antifungal activities (18). In addition, in another study, Sathi et al. (2002) isolated a yellowbrown antibiotic pigment with the structure of 4-hydroxy-nitrobenzene from Streptomyces species (19).

In a research in China (2009), it was observed that a purple pigment isolated from Streptomyces had a positive antimicrobial effect on Gramnegative/positive bacteria and fungi (20). With regard to the above-mentioned findings, the importance of identification of strains and new species of antibiotic pigment-producing actinomycetes is growing increasingly. Determination of the structure of pigments' compounds and removal of toxic compounds could lead to optimal use of these pigments.

\section{Conflict of interest}

The authors declare that there is no conflict of interests 


\section{References}

1. Chaudhary HS, Yadav J, Shrivastava AR, Singh S, Singh AK, Gopalan N. Antibacterial activity of actinomycetes isolated from different soil samples of Sheopur (A city of central India). J Adv Pharm Technol Res. 2013;4(2):118-23.

2. Dsouza M, Taylor MW, Turner SJ, Aislabie J. Genome-based comparative analyses of Antarctic and temperate species of Paenibacillus. PLoS One 2014;9(10):e108009.

3. Ribes JA, Vanover-Sams CL, Baker DJ. Zygomycetes in human disease. Clin Microbiol Rev 2000;13(2):236-301.

4. Valour F, Senechal A, Dupieux C, Karsenty J, Lustig S, Breton P, et al. Actinomycosis: etiology, clinical features, diagnosis, treatment, and management. Infect Drug Resist 2014;7:183-97.

5. Woznicka W. The Significance of Variation of Some Antibiotic Actinomycetes for the Taxonomy of Microorganisms of This Genus. Arch Immunol Ther Exp (Warsz) 1964;12:37-54.

6. Jose PA, Jebakumar SR. Phylogenetic diversity of actinomycetes cultured from coastal multipond solar saltern in Tuticorin, India. Aquatic biosystems 2012;8(1):23.

7. Krewski D, Yokel RA, Nieboer E, Borchelt D, Cohen J, Harry J, et al. Human health risk assessment for aluminium, aluminium oxide, and aluminium hydroxide. J Toxicol Environ Health B Crit Rev 2007;10 Suppl 1:1-269.

8. Mizukami H, Konoshima M, Tabata M. Variation in pigment production in Lithospermum erythrorhizon callus cultures. Phytochemistry 1978;17(1):95-7.

9. Gonzalez Holgado G, Castro Rodriguez J, Canedo Hernandez LM, Diaz M, Fernandez-Abalos JM, Trujillano I, et al. Radamycin, a novel thiopeptide produced by streptomyces sp. RSP9. I. Taxonomy, fermentation, isolation and biological activities. J Antibiot (Tokyo) 2002;55(4):383-90.

10. Maleki H, Mashinchian O. Characterization of Streptomyces Isolates with UV, FTIR Spectroscopy and HPLC Analyses. Bioimpacts 2011;1(1):47-52.

11. Chau R, Kalaitzis JA, Wood SA, Neilan BA. Diversity and biosynthetic otential of culturable microbes associated with toxic marine animals. Mar Drugs
2013;11(8):2695-712.

12. Gebreyohannes G, Moges F, Sahile S, Raja $\mathrm{N}$. Isolation and characterization of potential antibiotic producing actinomycetes from water and sediments of Lake Tana, Ethiopia. Asian Pac J Trop Biomed 2013;3(6):42635 .

13. Hussain MS, Fareed S, Ansari S, Rahman MA, Ahmad IZ, Saeed M. Current approaches toward production of secondary plant metabolites. J Pharm Bioallied Sci 2012;4(1):10-20.

14. Bokulich NA, Bamforth CW. The microbiology of malting and brewing. Microbiol Mol Biol Rev 2013;77(2):157-72.

15. McMurray, DN. Mycobacteria and Nocardia. In: Baron S, editor. Medical Microbiology. 4th edition. Galveston (TX): University of Texas Medical Branch at Galveston; 1996..

16. Ghannoum MA, Rice LB. Antifungal agents: mode of action, mechanisms of resistance, and correlation of these mechanisms with bacterial resistance. Clin Microbiol Rev 1999;12(4):501-17.

17. Morris-Jones R, Gomez BL, Diez S, Uran M, Morris-Jones SD, Casadevall A, et al. Synthesis of melanin pigment by Candida albicans in vitro and during infection. Infect immun 2005;73(9):6147-50.

18. Mayuran S, Radhakrishnan M, Balagurunathan R. Antimicrobial pigments from desert soil actinomycetes. In: proceeding of the National Symposium on "Recent Trends in Microbial Biotechnology". Sri Sankara Arts and Science College. 2006; p 35-51.

19. Sathi ZS, Sugimoto N, Khalil MI, Gafur M. Isolation of yellowish antibiotic pigment 4-hydroxy nitrobenzene from a strain of Streptomyces. Pak J Biol Sci 2002;52:201-3.

20. Wang L, Lei J, Xiang W, Jiang S, Sun J, Yang $Z$. Identification and characterization of purple pigmentproducing actinomycete Strain. Chin J Appl Environ Biol 2009;15(1):139-42.

\section{How to cite this article}

Azimi S, Basei Salehi M, Bahador N. Isolation and Identification of Streptomyces ramulosus from Soil and Determination of Antimicrobial Property of its Pigment. Mod Med Lab J. 2018;1(1):36-41. 